\title{
IMPORTÂNCIA DAS UNIVERSIDADES PÚBLICAS PARA A ECONOMIA LOCAL E REGIONAL: O CASO DA UNIOESTE E UTFPR EM FRANCISCO BELTRÃO, PR
}

Resumo: O objetivo deste artigo é analisar a dinâmica econômica do setor terciário de Francisco Beltrão, PR, destacando os serviços de educação, especificamente, as Instituições de Ensino Superior públicas (IES) e seus papéis de dinamização da economia local e regional onde estão inseridas. Assim, as IES desempenham importante papel no desenvolvimento regional, contribuindo para mitigar, as disparidades econômicas e sociais. Este artigo visa dimensionar o montante de recursos financeiros movimentados pelos campi de Francisco Beltrão da UNIOESTE e da UTFPR, bem como, verificar a espacialização das interações proporcionadas via procedência dos acadêmicos destas IES, o que por sua vez, permite aprofundar o entendimento da rede urbana e sua centralidade.

Palavras-chave: Dinâmica econômica. Rede urbana. Francisco Beltrão. Instituições de Ensino Superior públicas.

\section{IMPORTANCE OF THE PUBLIC UNIVERSITIES FOR LOCAL AND REGIONAL ECONOMY: THE CASE OF THE UNIOESTE AND UTFPR IN FRANCISCO BELTRÃO, PR}

Abstract: The objective of this article is to analyze the economic dynamic of the tertiary sector of Francisco Beltrão, Paraná, highlighting the services of education, specifically, public Higher Education Institutions (HEI) and their role of dynamization of the local and regional economy where they are inserted. Thus, the HEI play an important role in regional development, contributing to mitigate the economic and social disparities. This article aims to scale the amount of financial resources handled by the campuses of Francisco Beltrão at the UNIOESTE and the UTFPR, as well as, to verify a spatialization of the interactions provided by the origin of the academic of these PHEI, which, in turn, allows us to deepen the understanding of the urban network and its centrality.

Keywords: Economic dynamics. Urban network. Francisco Beltrão. Public higher education institutions.

\section{IMPORTANCIA DE LAS UNIVERSIDADES PÚBLICAS PARA LA ECONOMÍA LOCAL Y REGIONAL: EL CASO DE LA UNIOESTE Y UTFPR EN FRANCISCO BELTRÃO, PR}

Resumen: El objetivo de este artículo es analizar la dinámica económica del sector terciario de Francisco Beltrão, PR, destacando los servicios de educación, específicamente, las Instituciones de Enseñanza Superior públicas (IES) y sus papeles de dinamización de la economía local y regional donde están insertadas.

\footnotetext{
${ }^{1}$ Universidade Estadual do Oeste do Paraná, Francisco Beltrão, PR, Brasil, carlos.casaril@gmail.com https://orcid.org/0000-0001-9139-3919
} 
Así, las IES desempeñan un importante papel en el desarrollo regional, contribuyendo a mitigar, las disparidades económicas y sociales. Este artículo pretende dimensionar el monto de recursos financieros movidos por los campus de Francisco Beltrão de la UNIOESTE y de la UTFPR, así como verificar la espacialización de las interacciones proporcionadas vía procedencia de los académicos de estas IES, lo que a su vez permite profundizar el entendimiento de la red urbana y su centralidad.

Palabras clave: Dinámica económica. Red urbana. Francisco Beltrão. Instituciones de enseñanza superior públicas.

\section{Introdução}

As análises contidas aqui visam aprofundar o entendimento da dinâmica da rede urbana de Francisco Beltrão - Paraná, a partir das contemporâneas interações do setor terciário, especificamente os serviços de educação, mais precisamente das Instituições de Ensino Superior (IES) públicas presentes na cidade de Francisco Beltrão e analisar a respectiva dinâmica econômica e seus papéis na dinamização da economia local e regional.

A educação adquire importância decisiva no Brasil, sobretudo porque explica sozinha uma realidade em que, cada ano a mais de estudo possibilita o ganho de uma remuneração mais elevada e, por isso, diz respeito a uma das principais fontes de desigualdade na distribuição de renda e bem-estar social. A consolidação e ampliação de redes de Universidades Estaduais (como ocorre no Estado do Paraná) e uma rede de Universidades Federais e Institutos Federais de Educação ganham dimensão e importância basilares, sobretudo porque apresentam características locais e voltadas para o desenvolvimento regional.

Universidades Estaduais e Federais, portanto, públicas, são organizações sociais complexas que promovem ensino, pesquisa e extensão. As quais proporcionam amplo potencial para dinamizar a economia local e regional, além de criar um ambiente econômico local rico em oportunidades, sobretudo por propiciar crescimento econômico, acumulação de capital e capital humano.

Francisco Beltrão possui duas IES públicas, um campus da Universidade Estadual do Oeste do Paraná (UNIOESTE) e um campus da Universidade Tecnológica Federal do Paraná (UTFPR). Busca-se dimensionar o montante de recursos financeiros movimentados por estas duas IES, bem como, verificar a espacialização das interações proporcionadas via procedência dos acadêmicos destas IES, o que por sua vez, permite aprofundar o entendimento da rede urbana e sua centralidade. 
Estas dinamizam a centralidade de Francisco Beltrão, pois em dias letivos, centenas de pessoas saem das cidades da área de influência de Francisco Beltrão na rede urbana (IBGE, 2008) e mesorregião Sudoeste Paranaense e se dirigem para as salas de aulas, além é claro dos acadêmicos que são provenientes de cidades distantes do Estado do Paraná e de outros Estados, neste caso, os acadêmicos veem residir na cidade, trazendo consigo na maioria das vezes recursos para moradia/aluguel, alimentação, etc., o que proporciona aumento da dinâmica da economia urbana e regional.

As universidades públicas afetam o desenvolvimento local e regional onde estão inseridas, basicamente de três formas. Primeiro, através da formação de capital humano; Segundo, através das pesquisas e; Terceiro, a partir dos gastos relacionados ao funcionamento destas instituições. Esta terceira forma, representa um dos objetivos de análise deste trabalho.

O fato do enfoque deste estudo ter sido as IES públicas (universidades públicas) e não as universidades privadas se devem aos diferentes impactos produzidos por cada uma na economia urbana, municipal e regional. A universidade pública tem uma fonte externa de recursos, ou seja, os repasses do Estado e União (obtidos via arrecadação de impostos em todo o Estado, inclusive no município onde a universidade está instalada), estes repasses são (re)concentrados em poucos municípios. As IES públicas representam, de toda forma, um meio do estado reinserir estes recursos, os mesmos poderiam não retornar a determinada municipalidade caso tal instituição não estivesse ali instalada (LOPES, 2001).

Contudo, na universidade privada os recursos relacionados ao seu funcionamento decorrem do pagamento de mensalidades pelos alunos, sendo, deste modo, deduzidos da própria economia do município e região onde se localizam. No caso das universidades privadas, a inserção de recursos à economia municipal e regional restringe-se aos convênios e aos gastos de alunos oriundos de outros municípios. Destacando que, uma parte dos recursos obtidos pelas IES privadas via mensalidades cobradas dos alunos, retornam a economia municipal e/ou regional via remuneração dos professores e funcionários destas instituições privadas.

Os aspectos econômicos da universidade pública estão relacionados a três efeitos produzidos por estas instituições. O primeiro efeito associa-se a formação de capital humano. O segundo efeito associa-se as pesquisas. O terceiro efeito associa-se a dinamização (através da movimentação de recursos financeiros 
relacionados ao funcionamento das universidades) das economias dos municípios onde estas instituições estão localizadas (LOPES, 2001).

Mesmo entendendo-se aqui, que as universidades públicas possuem reconhecimento por parte da sociedade, especialmente, no que diz respeito à oferta de ensino. Buscou-se neste estudo como tema basilar, analisar as universidades públicas como fonte de dinamismo para a economia urbana, municipal e regional onde estão instaladas.

Este estudo permite um maior entendimento por parte da sociedade, especialmente da classe empresarial, dos políticos e da elite local e regional de questões importantes (como o investimento total realizado por estas IES com a remuneração dos servidores, estagiários, bolsistas, auxílios aos estudantes e auxílios alimentação) que podem suscitar novos aportes de investimentos privados e públicos.

$\mathrm{O}$ artigo foi dividido em quatro partes, sendo a introdução; os materiais e métodos; os resultados e discussões que se subdividiu em quatro etapas, na primeira apresenta-se uma discussão sobre a universidade pública e sua importância para o desenvolvimento local e regional, na segunda apresenta-se o conceito de rede urbana, a fim de permitir um entendimento da fundamentação teórica utilizada no trabalho e como à rede urbana seria uma possibilidade para análise regional, na terceira etapa desenvolve-se o exame sobre as universidades públicas como expressão de centralidade, buscando a partir do total de acadêmicos matriculados em 2016 nas IES analisadas, verificar a centralidade exercida por Francisco Beltrão e, na quarta e última etapa dos resultados e discussões, analisouse os impactos financeiros da UNIOESTE e da UTFPR, destacando que, com base em "novos" modelos de desenvolvimento regional endógeno, os impactos representados pelos recursos financeiros empenhados pelas IES, representariam aspectos concretos imperativos ao desenvolvimento; finalizando com as considerações e referências.

\section{Materiais e Métodos}

Para a realização da pesquisa, alguns procedimentos metodológicos e operacionais foram utilizados, estes tanto de caráter quantitativos como qualitativos.

Os procedimentos operacionais dizem respeito a trabalhos de campo, realizados, sobretudo, nas IES públicas instaladas em Francisco Beltrão, Paraná. 
Esta municipalidade possui duas IES públicas, um campus da Universidade Estadual do Oeste do Paraná (UNIOESTE) e um campus da Universidade Tecnológica Federal do Paraná (UTFPR). Busca-se dimensionar o montante de recursos financeiros movimentados por estas IES em 2016 com remuneração dos servidores Estaduais e Federais, estagiários, bolsistas, auxílios aos estudantes e auxílios alimentação, bem como, verificar a espacialização das interações proporcionadas via procedência dos acadêmicos, o que por sua vez, permite aprofundar o entendimento da rede urbana e sua centralidade. As informações necessárias foram obtidas junto a diversos setores da UNIOESTE, como direção geral, secretaria financeira, secretaria acadêmica, seção de recursos humanos, secretarias dos Programas de Pós-graduação Stricto Sensu e nos Centros de Ciências Humanas; Ciências Sociais Aplicadas e Ciências da Saúde. No campus da UTFPR de Francisco Beltrão, buscaram-se as informações necessárias com a direção geral e a secretaria acadêmica.

Buscou-se também, dimensionar o total da arrecadação correspondente ao ano de 2014 do município de Francisco Beltrão, as informações sobre a arrecadação municipal, foram adquiridas junto a Prefeitura Municipal de Francisco Beltrão, a Secretaria de Estado da Fazenda e junto ao Tesouro Nacional. Além de trabalhos considerados de gabinete, como revisão bibliográfica, coleta de dados secundários em diversas instituições, sobretudo no Instituto Brasileiro de Geografia e Estatística (IBGE).

Com a finalidade de avaliar a importância dos recursos financeiros movimentados em 2016 pelas IES públicas instaladas em Francisco Beltrão, realizou-se uma análise comparativa com a arrecadação tributária de 2014 do município, dando evidência a algumas categorias de receitas municipais.

Os dados foram tabulados e analisados, apresentando-se tabelas, quadros, mapa e figura, seguidos de análise descritiva.

\section{Resultados e Discussões}

\section{A universidade pública}

As pesquisas relacionadas sobre a temática das universidades, cada vez mais, apontam uma importância significativa conquistada pelas universidades públicas para o desenvolvimento local e regional (BOUCHER; CONWAY; MEER, 2001; LOPES, 2001; DINIZ et al, 2006; RAIHER, 2015; SHIKIDA et al, 2015), sendo 
abundantes os impactos trazidos à baila, principalmente a estruturação de um espaço propício a aprendizagem, a produção e ampliação de conhecimento, a formação de cidadãos com perspectiva humanista e habilitados a conduzir suas vidas profissionais nos mais diversos setores da sociedade, formação de lideranças, a concepção de empreendedorismos múltiplos e a perspectiva de originar uma visão estratégica sobre a dinâmica econômica, assegurando competitividade. Tais consequências derivam de múltiplas determinações entre as atividades de ensino, pesquisa e extensão, incluindo a oferta de serviços à comunidade (OECD, 2007).

Deste modo, as universidades públicas são organizações sociais complexas que promovem ensino, pesquisa e extensão. Cabendo as mesmas a geração, a sistematização e a transmissão de conhecimentos científicos, culturais, técnicos e tecnológicos.

Portanto, como se observa as universidades (sobretudo as públicas) são organizações sociais complexas que possuem uma importância significativa,

[...] seja por meio do fornecimento de mão de obra qualificada, beneficiando a produtividade, a organização social da região, gerando inovações, ofertando serviços para a comunidade, reproduzindo e criando conhecimento, atuando diretamente na economia via as suas despesas, dentre outros mecanismos (SHIKIDA et al, 2015, p. 76).

Universidades públicas são entidades sem fins lucrativos que se distinguem pelos diversos serviços que proporcionam a coletividade social. Destacando que, um de seus principais objetivos seria a maximização de bem estar social por meio da transformação de inputs em outputs.

[...] O principal input 'acadêmico' é o alunado, seguido de professores, laboratórios, bibliotecas, bolsas de estudo e os alojamentos estudantis. Os inputs 'sociais básicos' seriam aqueles relacionados a manutenção das atividades básicas das organizações, principalmente as verbas de custeio e investimento, a força de trabalho administrativa e as instalações físicas. Os inputs relacionados a 'ambiência geral' referem-se as condições regionais, políticas, institucionais e históricas (LOPES, 2001, p.49).

Os principais outputs consensuais seriam o ensino, a pesquisa e a extensão (os serviços). Os outputs do ensino seriam os diplomas das graduações, mestrados e doutorados e os certificados de eventos e especializações lato sensu, além do próprio aprendizado (LOPES, 2001). Já os outputs da pesquisa corresponderiam "[...] adição líquida ao estoque de conhecimentos disponível na sociedade" (MARINHO, 1996, p. 126). E os outputs da extensão, representados pelos serviços se constituiriam na prestação dos mais variados serviços, com destaque para os 
serviços hospitalares e nas demais atividades da extensão, como os cursos de curta e média duração e especializações lato sensu (LOPES, 2001).

Vale destacar que, além destes outputs caracterizados, as universidades públicas por serem instituições "PÚBLICAS" têm seus produtos destinados a sociedade.

\begin{abstract}
Contudo, partes dos produtos da universidade pública se revelam mais intensos nas economias onde estas instituições estão localizadas. É o caso, por exemplo, dos gastos financeiros relacionados ao funcionamento destas instituições [...]. A maioria destes gastos e todos os seus desdobramentos se repercutem com maior força sobre a economia dos municípios [e regiões] que possuem uma universidade pública [...] (LOPES, 2001, p.50).
\end{abstract}

A argumentação do autor supracitado acima vai de encontro com Rolim e Serra (2005) que advogam que esse efeito é denominado de efeito para traz, no qual, existiria um impacto direto sobre o fluxo de renda local, a partir dos gastos realizados pelas universidades com a remuneração dos servidores (docentes e funcionários), estagiários e bolsistas, os valores empregados nas compras de materiais e serviços diversos junto à economia local e regional. Resultando em aumento na renda familiar (mercado consumidor pujante), na receita do poder público, além de suscitar um efeito na demanda das empresas do mercado local.

Deste modo, os gastos executados pelas universidades públicas retornam num efeito multiplicador para a sociedade, permitindo a economia local e regional onde atuam as universidades, participar de parcela dos recursos governamentais que são subtraídos da sociedade via impostos e que neste caso retornariam. Neste efeito multiplicador também incluir-se-ia "[...] a formação do capital humano, beneficiando a produtividade local, a organização social da região, beneficia a criação direta e indireta de empregos, além de ter uma importância na geração de inovações e participação na geração de empresas de base tecnológica" (SHIKIDA, 2015, p.88).

Bandeira (1999) acrescenta ainda a este efeito multiplicador, um resultado sobre as regiões vizinhas às localidades onde estão instaladas as universidades, especialmente devido a muitos alunos procederem dessas municipalidades, permitindo, desta forma que sua atuação tenha abrangência efetivamente régio 


\section{Rede Urbana: uma possibilidade para análise regional}

A rede urbana configura-se como um recorte que possibilita uma análise do desenvolvimento regional. Estruturada em um conjunto de centros funcionalmente articulados, através de fixos e fluxos (CORRÊA, 1989). A partir da rede estruturamse as mais variadas atividades e interações, abrangendo centros urbanos dos mais variados níveis hierárquicos e complexidades estruturais, que por intermédio de suas relações (setor terciário e produtivo), promulgam etapas do desenvolvimento da divisão social e territorial do trabalho. "[...] Mas, envolve ainda outras funções urbanas ligadas à produção industrial, à circulação, à distribuição, gerando ampliações de atividades urbanas que podem atingir níveis de especializações produtivas" (FRESCA, 2010).

Sendo a rede urbana uma dimensão socioespacial da sociedade, constata-se que os processos de concepção, apropriação e circulação do valor excedente, frequentemente modificado, já que é integrado a divisão territorial do trabalho, estão igualmente em constante alteração. O que, todavia, possibilita o entendimento de que a "[...] rede urbana constitui-se simultaneamente em um reflexo da e uma condição para a divisão territorial do trabalho" (CORRÊA, 1989, p.48).

Seria reflexo, uma vez que, seria a partir de centralidades que localidades diferenciadas se formariam e se estruturariam uma hierarquia urbana, constituidora, por exemplo, de cidades comerciais, industriais, político-administrativas, universitárias, portuárias, dentre outras. É condição, devido ser a partir das funções exercidas pelos centros urbanos, que ocorrem à articulação dos mais variados setores econômicos, como, setor primário, secundário e terciário. A este último, incluem-se os subsetores, de comércio atacadista e varejista, de serviços de armazenagem, transporte, administrativo, financeiro, contábil, educação, saúde dentre outros. Deste modo, são nos centros urbanos inseridos em uma dada rede urbana, que ocorrem as condições necessárias para a produção, distribuição, circulação e consumo.

A rede urbana brasileira até meados da década de 1950 estava definida por um grau limitado de diversificação funcional. Sua importância relacionava-se a posição ocupada na hierarquia, segundo suas funções centrais conforme o modelo christalleriano.

Este modelo hierárquico supracitado foi estruturado pelo geógrafo alemão Walter Christaller, nomeando-se "teoria das localidades centrais", elaborada em 
1933 (CHRISTALLER, 1966). Este modelo demonstrou a presença de uma hierarquia entre cidades determinadas pela lógica da extração tributária e pelas necessidades da circulação mercantil estabelecidas permanentemente no território. Nesta teoria, qualquer estabelecimento comercial, industrial ou de prestação de serviços, fornece bens e serviços a uma região próxima do centro fornecedor, representando, nesse sentido, uma polarização espacial da aglomeração urbana. Proporcionando assim, a constituição de uma hierarquia de cidades, em que, no nível mais elementar, estariam as cidades produtoras basicamente de bens e serviços, aqueles mais procurados pela população para sua reprodução social cotidiana, e, do outro lado, estariam os centros maiores, geradores de produtos e serviços mais especializados para uma área territorial mais extensa.

A característica básica da teoria das localidades centrais, não é mais válida para Santos (1993, p.53), pois a rede urbana torna-se "Cada vez mais diferenciada, cada vez mais complexificada, cada cidade e seu campo respondem por relações específicas, próprias às condições novas da realização da vida econômica e social [...] Hoje, cada cidade é diferente da outra, não importa seu tamanho [...]". Essa nova particularidade da rede urbana, a de ser complexa e diferenciada se realiza de diversos modos a partir de suas inserções na divisão territorial do trabalho. Estas inserções podem ser por uma, ou várias produções propriamente ditas. Pois, cada rede e centro urbano se inserem distintamente nos processos de produção, distribuição, circulação e consumo, mesmo porque, no sistema capitalista de produção os centros melhores situados tenderam a se sobressair.

Portanto, a complexidade originária desta nova fase do desenvolvimento econômico-social se manifesta no fato de um centro urbano situar-se ao menos duas redes.

Assim, cada centro pode ter relações com centros de níveis hierárquicos mais elevados, não necessariamente sendo um centro do próximo nível hierárquico, as relações podem ser realizadas de um centro local diretamente com a metrópole nacional. Destacando que, o modelo teórico básico não se alterou, o que se alterou foram às múltiplas determinações de suas relações. Diante disso, a rede urbana brasileira pode sim ser analisada por meio da teoria Christalleriana, bastar-se-iam executar os complementos necessários para acompanhar a complexificação atual da sociedade e rede urbana.

A rede urbana de Francisco Beltrão é estruturada, a partir do núcleo urbano central (lugar central). Esta rede foi constituída a partir do estudo denominado de 
Regiões de Influência das Cidades (REGIC) (IBGE, 2008), o qual menciona que, a rede é formada pela cidade de Francisco Beltrão mais 24 centros urbanos que neste caso seria a região complementar (a área de influência), sendo esta rede polarizada por Cascavel (no Sudoeste Paranaense aparecem duas redes urbanas, uma polarizada por Francisco Beltrão e a outra por Pato Branco, as duas cidades que comandam a estruturação da vida regional, cada qual estruturada com uma área de influência).

Os centros urbanos desta rede desenvolveram uma urbanização reduzida, pois seu patamar era de apenas 16\%, em 1970 e evoluiu para 67,42\% em 2010. Nenhum centro da rede possuía população urbana superior a 50\%, em 1970 e em 1980, apenas Francisco Beltrão alcançara este índice (58,43\%). Já em 2010, 16 centros ultrapassaram os $50 \%$ de urbanização, ou seja, somente $64 \%$ dos centros da rede eram urbanos (IBGE, 2010).

Considera-se a maioria dos centros urbanos da rede de Francisco Beltrão como cidades locais, aquelas que estão na confluência do rural com o urbano (CORRÊA, 1999), sendo uma tarefa árdua diferenciá-las. Todavia, pode-se dizer que, quatro cidades da rede, Francisco Beltrão (núcleo central), Ampére, Dois Vizinhos e Realeza são cidades pequenas ${ }^{2}$. Francisco Beltrão apresenta-se em nível superior, devido sua dinâmica, o que permite até considerá-la como estando no limiar entre a cidade pequena, propriamente dita, e a cidade de porte médio, mas que, sobretudo, trata-se de uma cidade regional, pois possui uma capacidade de organização e direção da vida regional. Por esta dinâmica, Francisco Beltrão, possui atualmente, algumas funções só encontradas em cidades médias (em relação a estas funções, leia-se o poder centralizador estabelecido pelos serviços prestados na área de saúde regional; ensino médio e superior; comercial com a presença de algumas franquias nacionais, industrial, financeiro regional (sede de uma cooperativa de crédito), dentre outras). Vale relativizar que, Francisco Beltrão se enquadra na rede urbana nacional como um "Centro Sub-Regional A", porém seu enquadramento altera-se quando se analisa este centro urbano e sua rede no Estado do Paraná, ampliando-se ainda mais quando se verifica seu papel no Sudoeste Paranaense, neste último o papel/função de Francisco Beltrão pode ser

\footnotetext{
${ }^{2}$ As cidades que fazem parte da rede urbana de Francisco Beltrão estruturada a partir do REGIC (IBGE, 2008), podem ser visualizadas a partir da mancha de cor amarela na figura 1 deste artigo. Para maiores informações sobre a estruturação desta rede urbana, consultar IBGE, 2008 e CASARIL, 2014.
} 
considerado como uma cidade média, mas, sobretudo, uma cidade que possui características de comandar e gerir a região.

\section{As Universidade públicas como expressão de centralidade}

Conforme Sposito (1998) a análise da centralidade urbana pode ser realizada a partir da escala intra-urbana e/ou da escala da rede urbana (interurbana). Aqui se utilizou a segunda opção, que faz menção ao centro urbano "[...] ou aglomeração urbana principal em relação ao conjunto de cidades de uma rede, essa, por sua vez, podendo ser vista em diferentes escalas e formas de articulação e configuração, de maneira a que se possam compreender os papéis da cidade central" (SPOSITO, 1998, p.27).

Como se apresentou no subtítulo anterior, A rede urbana configura-se como um recorte que possibilita uma análise do desenvolvimento regional. A partir da rede estruturam-se as mais variadas atividades e interações, abrangendo centros urbanos dos mais variados níveis hierárquicos e complexidades estruturais. Buscase nesta parte demonstrar como se pode utilizar a partir da rede urbana, uma análise da dinâmica de interações espaciais contemporâneas entre centros urbanos, a fim de possibilitar a estruturação de uma análise regional, por meio da qual se possa verificar a centralidade desempenhada.

Para tanto, buscou-se a partir do total de acadêmicos matriculados em 2016 nas IES Públicas presentes na cidade de Francisco Beltrão, verificar a centralidade exercida por esta cidade. Destacando que, a centralidade de uma cidade,

\footnotetext{
[...] é função, acima de tudo, de sua capacidade de ofertar bens e serviços para outros centros urbanos, estabelecendo, desse modo, uma área de influência. Essa centralidade, portanto, é de natureza acima de tudo, econômica. Uma cidade será tanto mais complexa e possuirá uma posição tanto mais elevada na hierarquia da rede urbana, quanto mais ela possuir essa capacidade de ofertar bens e serviços e capturar uma área de influência maior. [...] (SOUZA, 2003, p.57).
}

Corrêa (1997) fez referência de que é preciso ponderar as especializações funcionais, sejam industriais ou aquelas vinculadas ao comércio e/ou serviços para analisar a centralidade urbana exercida por uma determinada cidade. Neste artigo, optou-se por considerar as atividades de prestação de serviços, principalmente, a educação, especificamente o ensino superior público. Estas atividades de serviços tiveram origem com a iniciativa de criar em Francisco Beltrão uma IES no ano de 1972. Contudo, a autorização para funcionamento da Faculdade de Ciências 
Humanas de Francisco Beltrão (FACIBEL), só ocorreu em 1975, com a participação do Centro Pastoral, Educacional e Assistencial Dom Carlos, de Palmas - PR (CASARIL, 2014).

Inicialmente, os cursos implantados na FACIBEL foram: Economia Doméstica e Estudos Sociais (este desativado em 1986, em seu lugar foi implantado o curso de Geografia, em 1987). Estes dois primeiros cursos foram reconhecidos pela Lei Federal n.83.343/79, de 17 de abril de 1979. O curso de Ciências Econômicas foi autorizado pelo Decreto n. 90.774, de 28 de dezembro de 1984 e, o curso de Pedagogia foi autorizado pelo Decreto de 16 de março de 1994, e em funcionamento as Habilitações das Matérias Pedagógicas do Ensino Médio, Magistério das Séries Iniciais do Ensino Fundamental e Magistério para Pré-Escola (Diário Oficial da União de 17 de março de 1994). Até a incorporação da FACIBEL pela UNIOESTE em 1997, funcionavam na instituição os cursos mencionados, que continuaram com a estadualização.

Este segmento de serviços ganha destaque na cidade abordada, principalmente a partir dos anos 2000 com a implantação em 2002 dos cursos de Administração e Direto, em 2013 iniciou as atividades do curso de Medicina, em 2015 iniciaram-se os dois últimos cursos de graduação até o momento Nutrição e Serviço Social (que nasceram a partir das negociações com o governo Estadual, pois este encerou as atividades do curso de Economia Doméstica, devido a baixa demanda social). Além destes, este campus da UNIOESTE somou ao Programa de Mestrado em Geografia, instalado em 2007, mais dois Programas: o Mestrado em Educação, instalado em 2012 e o Mestrado em Gestão e Desenvolvimento Regional, instalado em 2013. Sem esquecer que em 2017 entrará em funcionamento o Mestrado em Ciências da Saúde e o Doutorado em Geografia.

A Universidade Tecnológica Federal do Paraná, em Francisco Beltrão teve sua instalação em 2006, que em 2008 passou a ofertar o curso de Tecnologia em Alimentos, em 2009 o curso de Engenharia Ambiental. No segundo semestre de 2011 teve início o curso de licenciatura em Informática, o curso de Engenharia Química iniciou sua primeira turma no primeiro semestre de 2014, neste mesmo ano o curso de Tecnologia em Alimentos foi transformado em Engenharia de Alimentos. Além do Programa de Pós-graduação em Engenharia Ambiental (mestrado) que iniciou a primeira turma no primeiro semestre de 2017.

O quadro 01 e o mapa 01 apresenta o total de acadêmicos provenientes de cidades do Estado do Paraná que estudam nas IES Públicas de Francisco Beltrão - 
PR. A partir da visualização deste mapa verifica-se a centralidade de Francisco Beltrão proporcionada pelas IES públicas presentes na cidade. A cidade possui uma interação espacial com praticamente todas as regiões do Estado do Paraná, umas com maior intensidade e outras com intensidade média para fraca.

As duas IES públicas de Francisco Beltrão totalizaram 1.767 acadêmicos matriculados em 2016, entre graduandos e pós-graduandos, provenientes de cidades do Estado do Paraná. A UNIOESTE somou 1.307 acadêmicos, dos quais 631 são de Francisco Beltrão e os demais são de outras localidades paranaenses. Já a UTFPR totalizou 460 acadêmicos, sendo 268 de Francisco Beltrão. Dados que foram espacializados no mapa 1.

\begin{tabular}{|c|c|c|c|c|c|}
\hline \multicolumn{6}{|c|}{ PARANÁ } \\
\hline CIDADE & UNIOESTE & UTFPR & CIDADE & UNIOESTE & UTFPR \\
\hline Altônia & 1 & & Mangueirinha & & 2 \\
\hline Ampére & 29 & 12 & Manfrinópolis & 8 & 3 \\
\hline Apucarana & 1 & & $\begin{array}{l}\text { Marechal C. } \\
\text { Rondon }\end{array}$ & 2 & 3 \\
\hline Arapongas & 1 & & Marialva & 1 & \\
\hline Araruna & 2 & & Maringá & 12 & \\
\hline Assis Chateaubriand & 2 & & Mariópolis & 2 & \\
\hline Barbosa Ferraz & 1 & 1 & Marmeleiro & 58 & 18 \\
\hline Barracão & 9 & 2 & Medianeira & 3 & 1 \\
\hline Bela Vista da Caroba & & 1 & Missal & 1 & \\
\hline Bela Vista do Paraíso & 1 & & Nova Aurora & & 1 \\
\hline Bituruna & & 1 & Nova Esperança & 1 & \\
\hline Bom Jesus do Sul & 2 & 1 & $\begin{array}{l}\text { Nova Esperança } \\
\text { do SW }\end{array}$ & 10 & 1 \\
\hline Bom Sucesso do Sul & 6 & & Nova Laranjeiras & & 1 \\
\hline Cafelândia & 1 & & $\begin{array}{l}\text { Nova Prata do } \\
\text { Iguaçu }\end{array}$ & 16 & 2 \\
\hline Campina da Lagoa & 1 & & Nova Santa Rosa & & 1 \\
\hline Campo Largo & 1 & & Palmas & 3 & 5 \\
\hline Campo Mourão & 1 & 1 & Palotina & 2 & 1 \\
\hline Candói & & 1 & Paranagua & & 1 \\
\hline Cantagalo & 1 & & Paranavaí & 2 & \\
\hline Capanema & 10 & 2 & Pato Branco & 35 & 17 \\
\hline $\begin{array}{ll}\text { Capitão } & \text { Leônidas } \\
\text { Marques } & \\
\end{array}$ & 4 & 2 & Pérola d'Oeste & 2 & 2 \\
\hline Cascavel & 37 & 3 & Pinhais & & 1 \\
\hline Céu Azul & 1 & & $\begin{array}{l}\text { Pinhal de São } \\
\text { Bento }\end{array}$ & 1 & 2 \\
\hline Chopinzinho & 11 & 1 & Piraquara & & 1 \\
\hline Cianorte & 3 & & Planalto & 10 & 3 \\
\hline Clevelândia & 1 & & Ponta Grossa & 3 & 2 \\
\hline Colorado & & 1 & Porto Barreiro & 1 & \\
\hline Corbélia & 1 & 1 & Pranchita & 3 & \\
\hline Coronel Vivida & 8 & 4 & Quarto Centenário & 1 & \\
\hline Cruzeiro do Iguaçu & 5 & 1 & Quedas do Iguaçu & 7 & \\
\hline Cruzeiro do Oeste & 1 & & Realeza & 15 & 11 \\
\hline Curitiba & 23 & 9 & Renascença & 22 & 3 \\
\hline
\end{tabular}




\begin{tabular}{|c|c|c|c|c|c|}
\hline Dois Vizinhos & 46 & 13 & $\begin{array}{l}\text { Rio Bonito do } \\
\text { Iguaçu }\end{array}$ & 1 & 1 \\
\hline Enéas Marques & 14 & 2 & Salgado Filho & 24 & 1 \\
\hline Entre Rios do Oeste & 1 & & Salto do Lontra & 21 & 1 \\
\hline $\begin{array}{l}\text { Espigão Alto do } \\
\text { Iguaçu }\end{array}$ & 1 & & Santa Helena & & 1 \\
\hline Fazenda Rio Grande & 1 & & $\begin{array}{l}\text { Santa Izabel do } \\
\text { Oeste }\end{array}$ & 10 & 7 \\
\hline Flor da Serra do Sul & 13 & 1 & $\begin{array}{l}\text { Santo Ant. do } \\
\text { Sudoeste }\end{array}$ & 12 & 1 \\
\hline Formosa do Oeste & 1 & 1 & São João & 22 & 7 \\
\hline Foz do Iguaçu & 6 & 2 & $\begin{array}{l}\text { São João do } \\
\text { Triunfo }\end{array}$ & 1 & 1 \\
\hline Francisco Beltrão & 631 & 268 & $\begin{array}{ll}\text { São } & \text { Jorge } \\
\text { d'Oeste } & \end{array}$ & 9 & 2 \\
\hline Goioerê & 1 & & $\begin{array}{l}\text { São José dos } \\
\text { Pinhais }\end{array}$ & & 2 \\
\hline Guapirama & 1 & & $\begin{array}{ll}\text { São Mateus do } \\
\text { Sul }\end{array}$ & & 2 \\
\hline Guarapuava & 8 & & Saudade do Iguaçu & 5 & 1 \\
\hline Honório Serpa & & 1 & Sulina & 2 & 1 \\
\hline Ibema & 1 & & Tapejara & 1 & \\
\hline Indianópolis & 1 & 1 & Tapira & 1 & \\
\hline Iporã & 3 & & Telêmaco Borba & & 1 \\
\hline Irati & & 1 & Terra Rica & & 1 \\
\hline Itapejara d'Oeste & 34 & 5 & Toledo & 8 & 1 \\
\hline Laranjeiras do Sul & 1 & 1 & $\begin{array}{l}\text { Três Barras do } \\
\text { Paraná }\end{array}$ & 2 & \\
\hline Lindoeste & 1 & & Umuarama & 2 & 1 \\
\hline Loanda & 1 & & União da Vitória & & 1 \\
\hline Londrina & 6 & & Verê & 26 & 2 \\
\hline Luiziana & & 1 & Vitorino & 1 & 2 \\
\hline Mallet & 1 & & Vitorino & 1 & 2 \\
\hline SUB-TOTAL & 938 & 341 & SUB-TOTAL & 369 & 119 \\
\hline Total Geral PR & UNIOESTE & $\rightarrow \quad 1307$ & UTFPR & $\rightarrow \quad 460$ & \\
\hline
\end{tabular}

QUADRO 01 - Total de alunos provenientes de cidades do Estado do Paraná

Fonte: Secretaria Acadêmica da UTFPR, 2016; Secretaria Acadêmica da UNIOESTE, 2016; Secretaria do Programa de Pós-graduação em Geografia da Unioeste, 2016; Secretaria do Programa de Pós-graduação em Educação da Unioeste, 2016; Secretaria do Programa de Pós-graduação em Gestão e Desenvolvimento Regional da Unioeste, 2016.

Org.: O autor, 2016. 


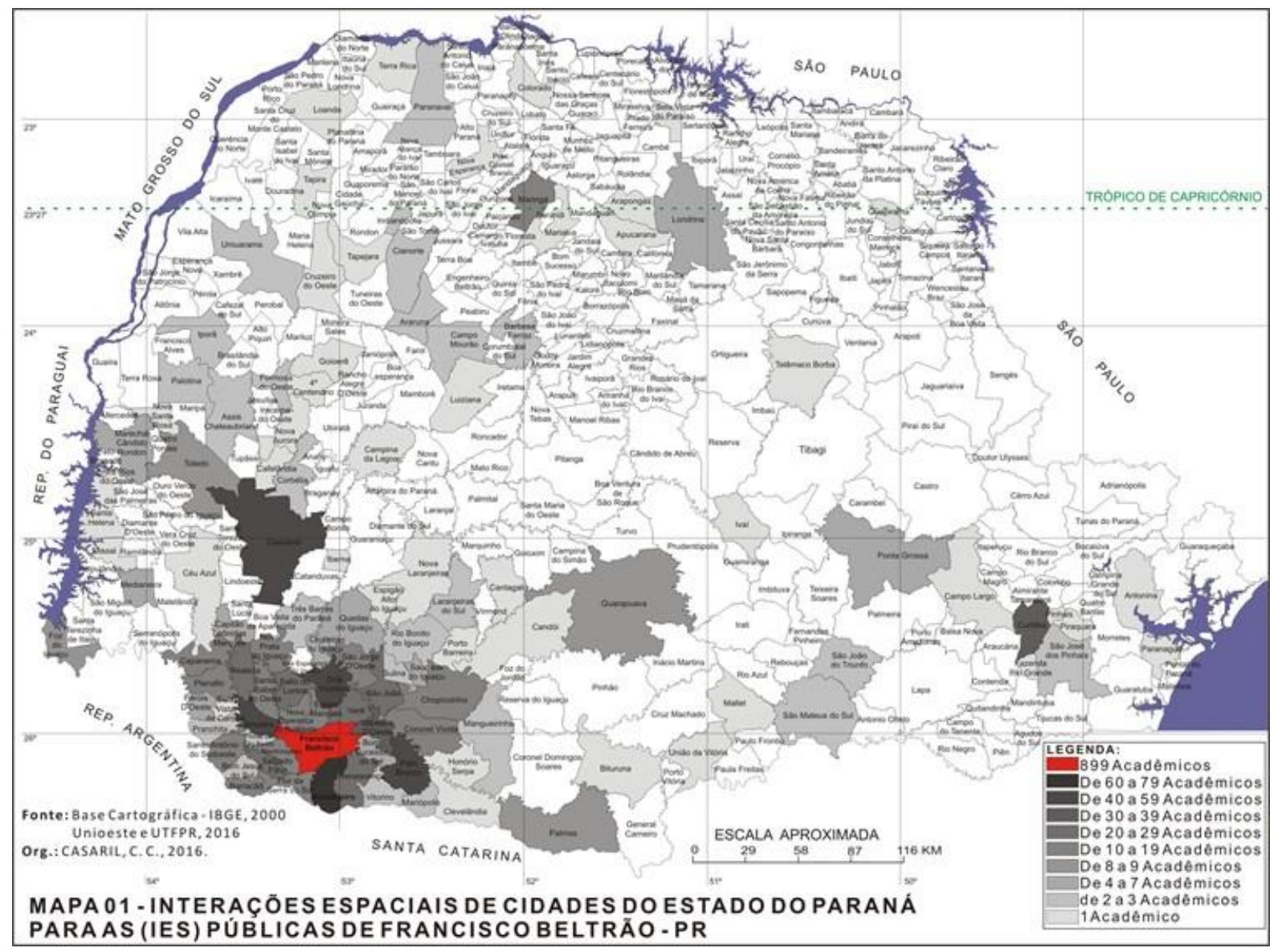

Os acadêmicos provenientes dos demais Estados somam um total de 294, sendo 126 na UNIOESTE e 168 na UTFPR. O Estado com maior representatividade em número de estudantes proveniente para as IES públicas de Francisco Beltrão é Santa Catarina, que conta com 124, destes 75 na UNIOESTE e 49 na UTFPR. $\mathrm{Na}$ sequência aparece o Estado de São Paulo com 92 estudantes provenientes para as IES públicas, sendo 22 para a UNIOESTE e 70 para a UTFPR. Os demais Estados que encaminham acadêmicos para Francisco Beltrão são BA, DF, ES, GO, MA, MG, MS, MT, PA, PB, PE, RJ, RO, RS, SE e TO.

Portanto, uma interação espacial que não alcança todos os Estados, mas atinge todas as cinco grandes regiões nacionais. A figura 1 abaixo permite ao leitor verificar as cidades e o número de estudantes provenientes para as IES públicas de Francisco Beltrão, fato que, amplia a centralidade urbana e a dinâmica da rede, pois segundo Corrêa (1997) quanto maior a área de influência, maior a população externa atendida e maior a sua centralidade. 


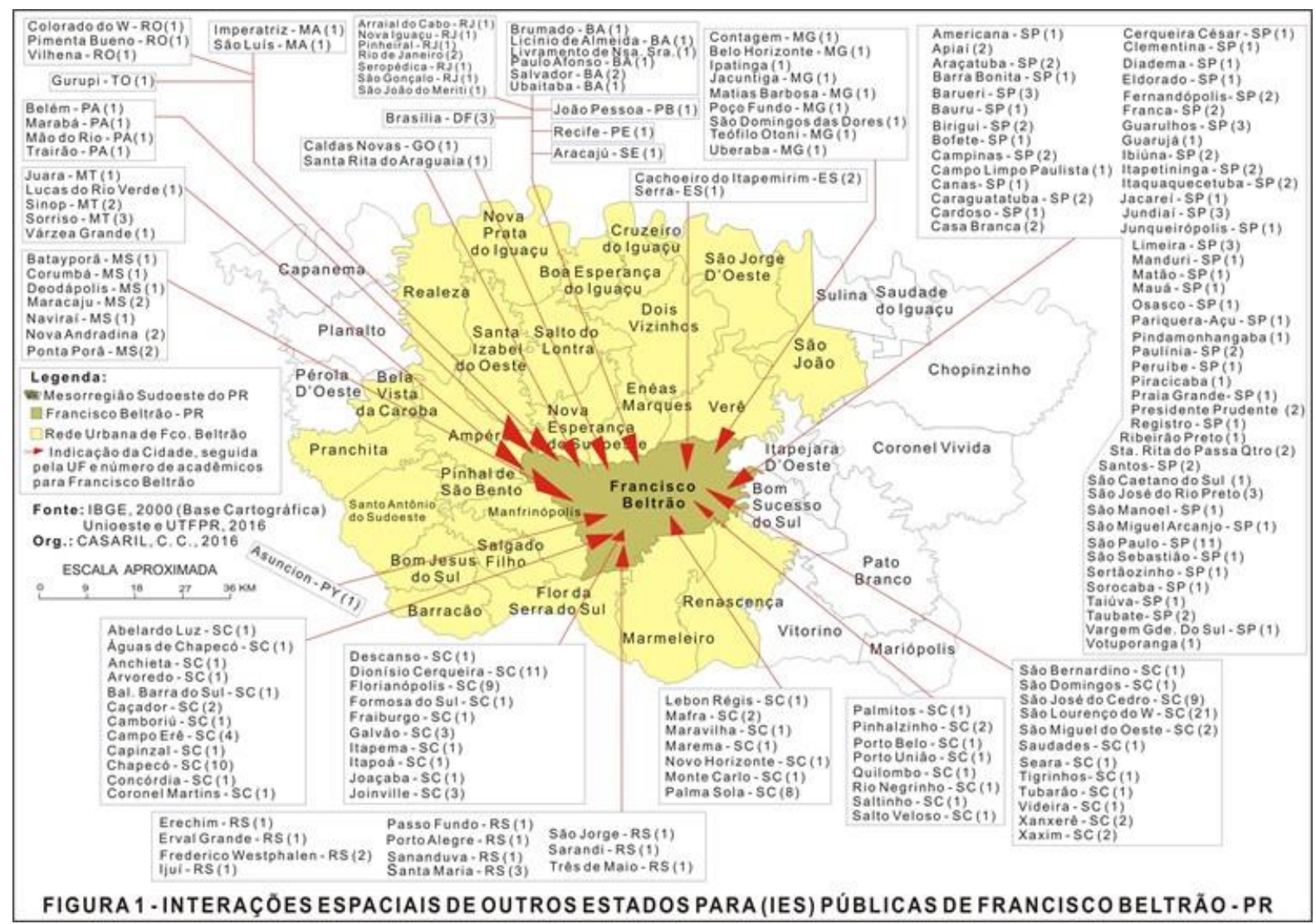

Quando somados o total de acadêmicos da UNIOESTE e da UTFPR provenientes do Estado do Paraná e dos demais Estados, totaliza-se 1.433 acadêmicos da UNIOESTE e 628 na UTFPR de Francisco Beltrão. Estas duas IES públicas somam 2.061 alunos. Destaca-se que, na soma do total destes alunos foi incluído o total de acadêmicos de graduação e de Pós-graduação (Stricto Sensu), devidamente matriculados em 2016.

Destacando que, os acadêmicos provenientes das cidades situadas no Sudoeste paranaense, somados aos acadêmicos procedentes das cidades localizadas no Oeste catarinense, mais especificamente aquelas situadas na divisa com o Sudoeste paranaense, deslocam-se diariamente ${ }^{3}$ (movimento pendular) a Francisco Beltrão para estudar, retornando as suas cidades após as aulas, o que por sua vez, confirma o grande fluxo rodoviário em horários de pico nas rodovias da região Sudoeste, estes fluxos realizam-se através das rodovias: PR-182, PR-180, PR-483, PR-475 e PR-566, todas chegando a Francisco Beltrão.

Uma questão importante a ser enfatizada aqui, pois representa uma oportunidade para ampliar a área de influência da rede, teria relação com o sistema

\footnotetext{
${ }^{3}$ Contudo, isso não quer dizer que alguns acadêmicos das IES de Francisco Beltrão procedentes de cidades circunvizinhas não possam estar residindo em Francisco Beltrão e, como já sabemos, muitos estão.
} 
de entrada nas IES. A UTFPR utiliza o sistema de entrada na instituição via Sistema de Seleção Unificada do Ministério da Educação (SISU) e a UNIOESTE a partir de 2014 modificou o sistema de entrada, onde 50\% das vagas são via Vestibular UNIOESTE e as restantes $50 \%$ das vagas são via SISU e, no SISU podem se candidatar a uma vaga alunos que prestaram o Exame Nacional do Ensino Médio (ENEM) residentes em qualquer localidade do país.

Em relação aos acadêmicos procedentes de outras regiões do Paraná e de outros Estados, devido à distância maior e a despesa para o deslocamento, transferem-se para Francisco Beltrão e fixam residência por tempo determinado, destacando que, "[...] A mobilidade espacial é função da renda, e isso influencia decisivamente a maneira como a rede urbana é vivenciada e a própria estrutura da rede [...]" (SOUZA, 2003, p.61).

A partir destas informações confirma-se a importância de Francisco Beltrão, ratificando a sua centralidade de Centro Sub-Regional A (IBGE, 2008). Como já se demonstrou neste trabalho, a rede de Francisco Beltrão polarizava 24 centros urbanos, conforme o REGIC (IBGE, 2008) e, pela análise aqui realizada, mesmo levando-se em conta apenas as atividades de serviços de ensino superior públicos e não abrangendo todas as especializações funcionais, quer sejam as produtivas, comerciais e/ou de serviços, constata-se que Francisco Beltrão possui uma região de influência ampla, e que tal, área de influência não ficaria restrita ao que nos informa o REGIC.

\section{Impactos financeiros das IES públicas de Francisco Beltrão (UNIOESTE e UTFPR)}

As IES públicas representam com base nos "novos" modelos de desenvolvimento regional (BOISIER, 1989), uma estratégia para o desenvolvimento regional e local endógeno. Com destaque para os impactos financeiros realizados pelas universidades públicas sobre a economia local e regional. Estes impactos representariam aspectos concretos que conjugariam múltiplos elementos e determinações imprescindíveis para o desenvolvimento. Assim, busca-se nesta parte da pesquisa dimensionar o montante de recursos financeiros movimentados pelas IES analisadas, como um dos elementos imperativos ao desenvolvimento local e regional. 
A UTFPR de Francisco Beltrão conta com 136 servidores efetivos e 11 contratados (substitutos), totalizando 147 servidores (entre docentes e agentes universitários). A remuneração bruta destes servidores soma $R \$: 1.205 .809,18$ e a remuneração líquida totaliza $R \$$ : 888.633,87.

A UTFPR de Francisco Beltrão distribui 18 bolsas de iniciação científica no valor de $R \$$ : 400,00 cada, totalizando, $R \$$ : 7200,00 mensais. Possui três Bolsas de Protagonismo Estudantil, totalizando $\mathrm{R} \$$ : 1.200,00 mensais. 76 alunos recebem auxílio estudantil mensal, este valor totaliza $R \$$ : $35.747,20$ mensais. A UTFPR repassa um total $R \$$ : $10.000,00$ mensais, com a política de auxílio alimentação. $A$ UTFPR possui oito estagiários, sendo quatro de nível superior e quatro de nível médio, a remuneração dos estagiários totaliza $R$ : 3.792,00 mensais.

Quando somadas as remunerações líquidas dos 147 servidores da UTFPR de Francisco Beltrão com a remuneração das bolsas de iniciação científica, auxílios estudantis, auxílios alimentação e estagiários, verificou-se que, esta IES injeta mensalmente na economia local e regional $R \$$ : 946.573,07.

A UNIOESTE possui 161 docentes em seu quadro de servidores, somam-se ainda 69 agentes universitários e oito estagiários (os estagiários realizam funções de 30 horas semanais, com remuneração de $R \$$ : $5,29 \mathrm{p} / \mathrm{h}$, os oito totalizam $R \$$ : $5.078,40$ mensais).

Quando somadas as remunerações dos salários e gratificações dos docentes e agentes universitários da UNIOESTE, verifica-se um valor bruto de proventos de $\mathrm{R} \$: 2.014 .503,96$, o valor líquido, quando retirado todos os descontos totaliza $\mathrm{R} \$: 1.494 .234,56$ mensais.

Atualmente, a UNIOESTE distribui também, 34 bolsas do Programa Institucional de Bolsas de Iniciação Científica (PIBIC) para graduandos de seus cursos. Sendo 18 bolsas PIBIC Ações Afirmativas de convênio Fundação Araucária/Unioeste no valor de $\mathrm{R} \$: 400,00$ cada. 10 bolsas PIBIC Unioeste no valor de $R \$ 300,00$ cada e seis bolsas PIBIC Cnpq no valor de $R \$: 400,00$ cada. Assim, as 34 bolsas do PIBIC totalizam $\mathrm{R} \$: 12.000,00$ mensais.

A UNIOESTE por meio do Centro de Ciências da Saúde foi contemplado pelo Programa de Educação pelo Trabalho para a Saúde - Pet Saúde/GraduaSus, uma parceria desta IES com a Secretaria Municipal de Saúde de Pato Branco. Este Programa possui seis bolsas no valor de $R \$$ : 400,00 para graduandos do Centro de Saúde (3 acadêmicos de Medicina e 3 acadêmicos de Nutrição). Duas bolsas no valor de $\mathrm{R} \$$ : 550,00 para docentes preceptores, um docente do curso de medicina e 
um de nutrição. Somam-se ainda, duas bolsas de $R \$$ : $1.100,00$ para docentes coordenadores, sendo uma para docente do curso de medicina e uma para docente do curso de nutrição. Este programa Pet Saúde/GraduaSus repassa $R \$$ : $5.700,00$ mensais, via pagamento de bolsas.

A UNIOESTE em Francisco Beltrão possui quatro Programas de Pósgraduação, Geografia; Educação; Gestão e Desenvolvimento Regional e Ciências da Saúde que entrou em funcionamento no primeiro semestre de 2017. Em 2017 entrou em funcionamento também o Doutorado em Geografia.

O Programa de Pós-graduação em Geografia possui 19 bolsas para mestrandos (sendo 17 da Capes, uma do Cnpq e uma da Fundação Araucária). Possui também, uma bolsa de Pós-doutorado do Programa Nacional de PósDoutorado (PNPD-Capes). As bolsas de mestrado possuem o valor de $R \$: 1.500,00$ (Capes e Cnpq) e R\$: 1.800,00 (Fundação Araucária). A bolsa do PNPD-Capes totaliza R\$: 4.100,00. Assim, o Programa de Pós-graduação em Geografia distribui $\mathrm{R} \$$ : 32.900,00 mensalmente, por meio de bolsas.

O Programa de Pós-graduação em Educação possui sete bolsas de mestrado, sendo quatro da Capes; duas da Capes/Fundação Araucária ( $\mathrm{R} \$$ : 1.800,00) e uma da Capes/Fundação Araucária ( $R$ \$: 1.500,00), além de uma bolsa do PNPD-Capes. Assim, este programa distribui R\$: 15.200,00 mensalmente.

Já o Programa de Pós-graduação em Gestão e Desenvolvimento Regional possui sete bolsas de mestrado (cinco da Capes de $R \$$ : 1.500,00 e duas da Capes/Fundação Araucária de R\$: 1.800,00) e uma do PNPD-Capes. Deste modo, este programa distribui um total de $R \$$ : $15.200,00$ mensalmente.

Portanto, os Programas de Pós-graduação da UNIOESTE repassam para seus alunos bolsistas um total de $\mathrm{R} \$$ : $63.300,00$ mensalmente. Valor este injetado na economia de Francisco Beltrão e região.

A UNIOESTE em Francisco Beltrão possui alguns programas e projetos, a partir de determinados convênios, o quadro 2 abaixo nomeia os programas e projetos e apresenta os tipos de bolsas, seus valores, quantidades de bolsas e o total mensal.

Quando somadas as remunerações líquidas dos 230 servidores da UNIOESTE de Francisco Beltrão com a remuneração das bolsas dos diversos convênios, bolsas de iniciação científica, bolsas mestrado, bolsas Pós-doutorado e estagiários, verificou-se que, está IES injeta mensalmente na economia local e regional $\mathrm{R} \$: 1.644 .237,96$. 


\begin{tabular}{|c|c|c|c|c|}
\hline Projeto/Convênio & Tipo de Bolsa & Valor unitário & Qte mensal & Total mensal \\
\hline \multirow{3}{*}{$\begin{array}{l}\text { Programa Bom } \\
\text { Negócio Paraná }\end{array}$} & Bolsas Orientadores & $1.030,00$ & 2 & $2.060,00$ \\
\hline & Bolsa Recém-formados & $2.000,00$ & 4 & $8.000,00$ \\
\hline & Bolsa Graduandos & 745,00 & 3 & $2.235,00$ \\
\hline \multirow{3}{*}{ Programa Patronato } & Bolsas Orientadores & $1.030,00$ & 5 & $5.150,00$ \\
\hline & Bolsa Recém-formados & $2.000,00$ & 4 & $8.000,00$ \\
\hline & Bolsa Graduandos & 745,00 & 5 & $3.725,00$ \\
\hline \multirow{3}{*}{ Programa NEDDIJ } & Bolsas Orientadores & $1.030,00$ & 2 & $2.060,00$ \\
\hline & Bolsa Recém-formados & $2.000,00$ & 4 & $8.000,00$ \\
\hline & Bolsa Graduandos & 745,00 & 3 & $2.235,00$ \\
\hline \multirow{3}{*}{$\begin{array}{l}\text { Demais } \\
\text { USF }\end{array}$} & Bolsas Orientadores & $1.030,00$ & 3 & $3.090,00$ \\
\hline & Bolsa Recém-formados & $1.880,00$ & 5 & $9.400,00$ \\
\hline & \begin{tabular}{|l|} 
Bolsa Graduandos \\
\end{tabular} & 745,00 & 6 & $4.470,00$ \\
\hline \multirow{3}{*}{$\begin{array}{l}\text { Diversos Convênios } \\
\text { Unioeste/Fundação } \\
\text { Araucária* }\end{array}$} & Bolsas Iniciação Científica & 400,00 & 1 & 400,00 \\
\hline & Bolsa Apoio Técnico à Pesquisa & $1.100,00$ & 1 & $1.100,00$ \\
\hline & Bolsas Produtividade & $1.000,00$ & 4 & $4.000,00$ \\
\hline \multicolumn{3}{|l|}{ TOTAL MENSAL } & 52 & $63.925,00$ \\
\hline
\end{tabular}

QUADRO 02 - Bolsas de Programas e Projetos de diversos convênios

Fonte: Secretaria Financeira da UNIOESTE, Campus de Francisco Beltrão, PR, 2016.

* Obs.: Os valores das bolsas de mestrado, repassadas aos Programas de Pós-graduação, por meio do convênio da UNIOESTE com Fundação Araucária foram retirados desta tabela e incluídos diretamente na soma dos valores repassados por cada Programa.

Deste modo, as duas IES públicas, universo desta análise, injetam juntas $\mathrm{R} \$: 2.590 .811,03$ mensais, o que corresponde a $\mathrm{R} \$$ : $31.089 .732,36$ colocados anualmente na economia local e regional.

Não foram contabilizados os recursos financeiros de despesas de custeio, investimentos e receitas próprias ${ }^{4}$ movimentadas pela UNIOESTE e pela UTFPR, apenas foram somadas as despesas com pessoal (remuneração dos servidores, estagiários, bolsistas, auxílios estudantis e auxílios alimentação).

Neste trabalho, deixou-se também, de avaliar os impactos financeiros decorrentes dos gastos dos acadêmicos de outras cidades. Isto porque como se observou no decorrer deste trabalho, $43 \%$ dos acadêmicos do campus de Francisco Beltrão da UNIOESTE e da UTFPR procedem de outros municípios, alguns destes, devido residir em localidades distantes se mudaram para Francisco Beltrão, outros

\footnotetext{
${ }^{4}$ Vale destacar que, os recursos financeiros de despesas de custeio, investimentos e não foram incluídos neste trabalho, sobretudo, devido a maior parte de estes recursos serem empenhadas via licitações e muitas das empresas vencedoras de processos licitatórios serem de localidades fora dos limites regiões do Sudoeste Paranaense, o que traria grande dificuldade, pois todos os processos licitatórios em vigor teriam que ser abertos para uma previa verificação das empresas que estão sediadas na região, pois um dos objetivos do trabalho é analisar a dinâmica econômica local e região proporcionada pelas IES públicas.
} 
por residir em localidades mais próximas, na área de influência de Francisco Beltrão fazem viagens diárias (movimentos pendulares).

Alguns irão falar que as IES trazem uma maior dinâmica local, mas não regional. A argumentação deste trabalho é no sentido de que, tanto o local como o regional são impactados, basta verificar, por exemplo, o mapa 1, pois nele o leitor visualiza que a maior parte dos acadêmicos provenientes de outros municípios, nesse caso excetuando Francisco Beltrão, provêm do Sudoeste Paranaense, se usar a terminologia da centralidade urbana/da rede urbana, verificar-se-á que os acadêmicos estão espacializados na área de influência de Francisco Beltrão.

Assim, devido as Universidades promoverem o desenvolvimento do ensino, pesquisa e extensão, promovem ao mesmo tempo uma dinamização da economia local (Lopes, 2001) e por que não regional, pois seus egressos terão uma formação intelectual, cultural e social que Ihes permitiram auferir um maior rendimento, além disso, a princípio trará um aumento da produtividade, devido sua formação qualificada, o que por sua vez, gerará uma dinamização da economia local e regional.

O fato do enfoque deste estudo ter sido as IES públicas e não as IES privadas se devem aos diferentes impactos produzidos por cada uma na economia urbana, municipal e regional. A universidade pública tem uma fonte externa de recursos, ou seja, os repasses do Estado e União (obtidos via arrecadação de impostos em todo o Estado, inclusive no município onde a universidade está instalada), estes repasses são (re)concentrados em poucos municípios. As IES públicas representam, de toda forma, um meio do estado reinserir estes recursos, os mesmos poderiam não retornar a determinada municipalidade caso tal instituição não estivesse ali instalada.

Contudo, na IES privada os recursos relacionados ao seu funcionamento decorrem do pagamento de mensalidades pelos alunos, sendo, deste modo, deduzidos da própria economia local e regional. No caso das IES privadas, a inserção de recursos à economia municipal e regional restringe-se aos convênios e aos gastos de alunos oriundos de outros municípios (LOPES, 2001). Destacando que, uma parte dos recursos obtidos pelas IES privadas via mensalidades cobradas dos alunos, retornam a economia municipal e/ou regional via remuneração dos professores e funcionários destas instituições privadas.

As universidades públicas afetam o desenvolvimento local e regional onde estão inseridas, basicamente de três formas. Primeiro, através da formação de 
capital humano; Segundo, através das pesquisas e; Terceiro, a partir dos gastos relacionados ao funcionamento destas instituições. Esta terceira forma, por sua vez, representa um dos objetivos de análise deste trabalho.

Em relação à formação de capital humano, seu impacto no desenvolvimento local e regional está dado e, é reconhecido por toda sociedade. Quanto às pesquisas desenvolvidas pelas universidades públicas, possuem colaboração no sentido de que, além de ampliar o acervo de conhecimento da sociedade, determinam o progresso técnico e a formação de novos empreendimentos, fornecendo as bases para o desenvolvimento econômico.

Mesmo entendendo-se aqui, que as universidades públicas possuem reconhecimento por parte da sociedade, especialmente, no que diz respeito à oferta de ensino. Buscou-se neste estudo como tema basilar, analisá-las como fonte de dinamismo para a economia urbana, municipal e regional onde estão instaladas.

Este estudo permite um maior entendimento por parte da sociedade, especialmente da classe empresarial, dos políticos e da elite local e regional de questões importantes (como o total de recursos financeiros mobilizados pelas IES públicas, somando-se nesta análise o total das remunerações dos servidores, estagiários, bolsistas, auxílios aos estudantes e auxílios alimentação) podem suscitar novos aportes de investimentos privados e públicos, gerando assim, a possibilidade de transformar "fatores dados" em "fatores dinâmicos", equivalendo-se, deste modo, a dotar o local e o regional (setor empresarial) para suprir as necessidades dadas pela demanda das instituições, do seu corpo docente, discente e dos demais servidores.

Como este estudo trata de impactos sobre a economia, buscou-se identificar as remunerações líquidas dos servidores, estagiários, bolsistas e dos auxílios. Para tanto, do valor bruto da massa salarial, deduziu-se a parcela retida para impostos de renda e a parcela destinada as contribuições previdenciárias, assistencial entre outras, que foram obtidas com auxílio da secretaria financeira e de recursos humanos das IES analisadas. E, já que dos repasses aos bolsistas e auxílios não incidem deduções de impostos, chegou-se, desta forma, a renda total disponível para professores, funcionários, estagiários e alunos (bolsistas ou que recebem determinados auxílios), verificando-se assim, o impacto provocado na economia urbana, municipal e regional.

Vale destacar que, neste trabalho não foi estimada qual seria a parcela de gastos que os docentes, discentes, funcionários e estagiários teriam a propensão de 
realizar no local, no regional e a parcela que teria a propensão de ser extraída da economia local (neste sentido encontrar-se-iam os gastos em outras localidades e as compras online cada vez mais comuns).

Em relação ao desenvolvimento regional endógeno, o impacto financeiro de uma universidade pública sobre a economia municipal suscita múltiplos elementos efetivos para o desenvolvimento local.

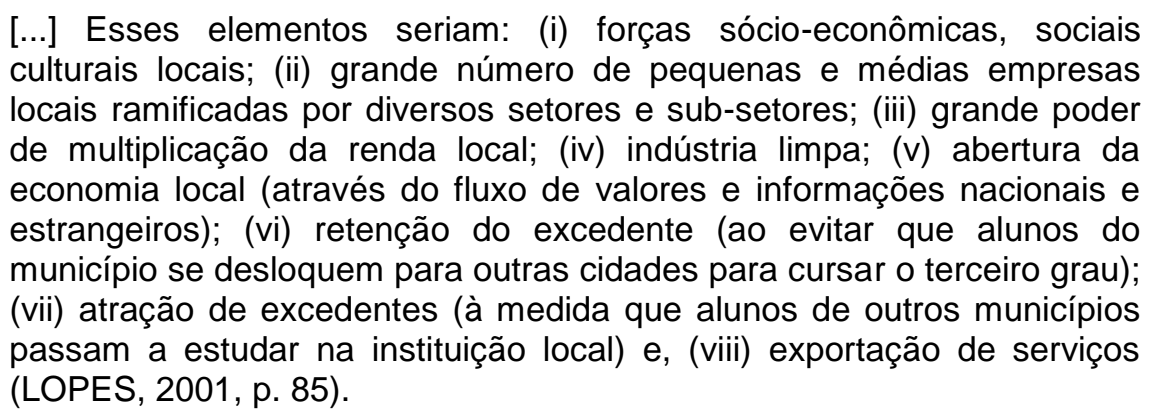

Com a finalidade de avaliar a importância dos recursos financeiros movimentados pelas IES analisadas, realizou-se um comparativo com a arrecadação do município, assim, a tabela 01 apresenta as categorias e os valores de arrecadação do município.

A movimentação de recursos financeiros destas IES, em 2016 foi da ordem de $R \$: 31.089 .732,36$ montante proveniente de recursos do tesouro do estado do Paraná e do tesouro nacional. Desta forma a arrecadação tributária do município representa um importante parâmetro comparativo para avaliar sua importância.

Tabela 01 - Arrecadação do município de Francisco Beltrão, 2014. Em Reais

\begin{tabular}{|l|r|}
\hline ICMS - Quota Parte (Repasse Líquido) & $27.127 .237,25$ \\
\hline Fundo de Exportação & $436.612,90$ \\
\hline Royalties do Petróleo & $12.347,04$ \\
\hline IPVA $^{*}$ & $9.394 .903,48$ \\
\hline Receita Tributária própria* & $30.822 .285,95$ \\
\hline Fundo de Participação dos Municípios & $27.554 .193,05$ \\
\hline
\end{tabular}

Fonte: Secretaria de Estado da Fazenda, Tesouro Nacional e Prefeitura de Francisco Beltrão.

* Imposto sobre Propriedade de Veículos Automotores

** A Receita Tributária própria provêm dos impostos (IPTU - Imposto Predial e Territorial Urbano) + (IR- Imposto sobre a Renda e Proventos de Qualquer Natureza) + (ITBI - Imposto sobre Transmissão de Bens Imóveis) + (ISSQN - Imposto sobre Serviços de Qualquer Natureza), somam-se ainda as taxas (Taxas de Exercício do poder de polícia) + (Taxas de Prestação de Serviços) e a Contribuição de Melhoria.

Org.: O autor, 2016.

Tabela 02 - Relação entre o total dos recursos financeiros movimentados e algumas categorias de receita do município, 2014. Em Reais.

\begin{tabular}{|l|r|r|r|}
\hline $\begin{array}{l}\text { Recursos financeiros das IES Públicas } \\
\text { (Unioeste + UTFPR) }\end{array}$ & $31.089 .732,36$ & $=\mathrm{A} / \mathrm{B}$ & $114,61 \%$ \\
\hline Quota-parte ICMS (B) & $27.127 .237,25$ & $=\mathrm{A} / \mathrm{C}$ & $112,83 \%$ \\
\hline
\end{tabular}




\begin{tabular}{|l|r|r|r|}
\hline Fundo de participação do município (C) & $27.554 .193,05$ & $=$ A/D & $100,87 \%$ \\
\hline Receita Tributária própria (D) & $30.822 .285,95$ & \multirow{2}{*}{ = A/E } & $330,92 \%$ \\
\cline { 1 - 2 } IPVA (E) & $9.394 .903,48$ &
\end{tabular}

Fonte: Secretaria de Estado da Fazenda, Tesouro Nacional, Prefeitura de Francisco Beltrão, UNIOESTE e UTFPR campus de Francisco Beltrão.

* Total dos recursos financeiros, já mencionados no decorrer do trabalho (remuneração servidores + estagiários + bolsistas + auxílios estudantes e auxílios alimentação), 2016.

Org.: O autor, 2016.

Nas comparações entre a arrecadação correspondente ao ano de 2014 do município de Francisco Beltrão e os recursos movimentados pelas IES públicas que estamos analisando, apresentado na tabela 02 acima, verifica-se a importância destas IES. Esta relação mostra que as receitas das IES correspondem a 100,87\% da receita tributária própria do município. No que diz respeito à quota-parte do município na arrecadação do ICMS os recursos movimentados pela UNIOESTE e UTFPR, campus de Francisco Beltrão correspondem a 114,61\%. Já em relação à arrecadação do IPVA em relação aos recursos das IES, este supera os 330,92\%.

Deste modo, esta verificação de recursos financeiros movimentados pelas universidades em relação a algumas categorias de receitas municipais permitiu auferir a importância da UNIOESTE e da UTFPR como vetor de recursos tributários que retornam, por meio da remuneração dos servidores Estaduais e Federais, dos estagiários, bolsistas e dos auxílios estudantis e de alimentação que são injetados na economia local e regional.

Este estudo, embora verifique o total da remuneração dos servidores, bolsistas, auxílio aos estudantes e auxílio alimentação e faça referencia de que o valor obtido será injetado na economia local e regional, sabe-se que com a globalização e novas tecnologias da informação e comunicação (internet), grande parte deste recurso é destinada a compras online. Portanto, este estudo, não identifica os possíveis vazamentos que ocorreriam na economia do município, por exemplo, com o total dos gastos realizados em outras localidades e regiões e, com o total desviado da economia se não existisse estas IES que estamos analisando. Trata-se dos alunos da UNIOESTE e da UTFPR que, na ausência destas instituições, estariam cursando o ensino superior em outras cidades e regiões. Portanto, causando vazamento de recursos na economia do município correspondente aos gastos com a manutenção destes alunos nestas cidades.

Calculou-se o impacto potencial e não o impacto efetivo em função das "fugas" e da dificuldade de mensurá-la. Como se verificou, o impacto das IES públicas sobre a economia de Francisco Beltrão e região atingiu a cifra de $R \$$ : 
31.089.732,36 em 2016. No entanto, devido estar em uma economia capitalista e globalizada, como se fez referência no parágrafo anterior, parte considerável dos produtos adquiridos pelo mercado consumidor municipal provêm de outros municípios, regiões e países e parte variável dos recursos são gastos em outras localidades, portanto, não inseridos diretamente na economia local. Portanto, a renda gerada a partir das IES que estamos analisando tem parte de sua reprodução, ou seja, multiplicação, em outras municipalidades.

Estas IES ajudaram a ampliar a centralidade urbana de Francisco Beltrão, sendo que esta faz parte da escala da rede urbana (interurbana), que todavia, dinamiza a escala intra-urbana, pois esta centralidade vem acompanhada de mudanças econômico-sociais no espaço urbano, principalmente, no que diz respeito ao mercado imobiliário, através da percepção dos agentes construtores, corretores imobiliários, proprietários fundiários etc., que ao visualizarem uma demanda solvável, investem no mercado imobiliário, através da construção de "kitchenettes" geminadas, edifícios de 4 pavimentos, normalmente com 4 apartamentos por andar, voltados na maioria das vezes ao aluguel, formando a classe rentiers (isso é uma das razões da valorização do preço do solo urbano em bairros com "melhores" acessibilidades a área central da cidade e das universidades, o que por sua vez, amplia a segregação sócio espacial que exclui a parcela da população de menor poder aquisitivo para bairros periféricos). Além da dinâmica do capital imobiliário, o comércio e os serviços seguem o mesmo caminho de intensificação, motivados pelo aumento da demanda proporcionada pela chegada de acadêmicos e professores que passam a fazer parte do mercado consumidor da cidade. Isso nos faz verificar a importância, que o ensino superior vem constituindo-se para Francisco Beltrão, inclusive na estruturação de Polo Universitário, ampliando a qualificação de mão de obra regional.

\section{Considerações Finais}

Neste trabalho verificou-se a dinâmica atual da rede urbana de Francisco Beltrão e sua centralidade, constatando as interações realizadas pelo setor terciário, especificamente das Instituições de Ensino Superior públicas, UNIOESTE e UTFPR.

Uma questão importante foi verificar que, os centros urbanos da rede analisada, situam-se pelo menos duas redes, a primeira estruturada pela teoria das localidades centrais, portanto, uma rede mais rígida e sistemática, onde centros 
locais mantêm relações com a área rural e com os centros de sua rede e, a segunda menos rígida e estruturada por fluxos irregulares.

Segundo o REGIC (IBGE, 2008), Francisco Beltrão polariza uma rede urbana que compreende outros 24 centros, porém constatou-se que no que se refere às universidades públicas, Francisco Beltrão expressa uma centralidade muito mais ampla do que a informada pelo mesmo REGIC, pois a rede estruturada pelas IES públicas é menos rígida e formada por fluxos irregulares, portanto, não é estruturada pela teoria das localidades centrais.

Outra questão importante verificada por este trabalho, diz respeito ao dimensionamento do montante de recursos financeiros movimentados pela UNIOESTE e pela UTFPR, bem como sua comparação com a arrecadação do município de Francisco Beltrão em relação a categorias de receitas municipais determinadas, pois permitiu verificar a importância das universidades como vetores de recursos tributários que retornam do Estado e da União para serem injetados na economia local e regional. Comprovando assim que o retorno econômico para a sociedade não ocorre, apenas, através do desenvolvimento das suas atividades fins: o ensino, a pesquisa e a extensão.

Assim, as Universidades públicas significam muito mais do que instituições voltadas a disseminar conhecimento técnico, tecnológico, científico e intelectual, beneficiando o local e a região onde estão inseridas com uma ampliação da qualificação da mão de obra, pois, além disso, significam uma possibilidade dada de desenvolvimento econômico local e regional.

As universidades públicas constituem vetores de desenvolvimento econômico regional, com custos relativamente baixos, se levar em conta os recursos e as renúncias fiscais outorgados pelo poder público para a implantação de grandes e médias empresas. De tal modo que, o crescimento da UNIOESTE e UTFPR provoca não só desenvolvimento sociocultural, mas ao mesmo tempo crescimento econômico para Francisco Beltrão e sua área de influência na mesorregião sudoeste paranaense.

Como uma sugestão que se poderia levantar neste momento, estaria implícita a proposta para que os gestores da IES públicas disponibilizassem de forma digital, mensalmente, informes com os dados do dimensionamento dos recursos financeiros movimentados por cada uma das IES públicas, pois esta seria uma forma, de servir de orientação a agentes privados e públicos para as mais diferentes ações que podem suscitar novos aportes de investimentos, gerando assim, a possibilidade de 
transformar "fatores dados" em "fatores dinâmicos", equivalendo-se, deste modo, a dotar o local e o regional (vide o setor empresarial) para suprir as necessidades determinadas pela demanda das instituições, do seu corpo docente, discente e dos demais servidores. Contribuindo, deste modo, com o empreendedorismo e a geração de empregos e rendas.

\section{REFERÊNCIAS}

BANDEIRA, P. S. Participação, articulação de atores sociais e desenvolvimento regional. Textos para discussão, n.630. Rio de Janeiro: IPEA, 1999.

BOISIER, S. Política Econômica, organização social e desenvolvimento regional. In: HADDAD, P. R. (Org.). Economia Regional: teoria e métodos de análise. Fortaleza: Banco do Nordeste do Brasil S. A., 1989. p. 589-687.

BOUCHER, G.; CONWAY, C; MEER, E. The role of universities in the development of less favoured regions. Gateway 8: Local and Regional Cooperation: Baltic to the Mediterranean Congress. In: Abstract for Regional Studies Association Conference, Gdansk, Polônia, p.15-18, September, 2001. Disponível em $<$ www.regionalstudiesassoc.ac.uk/events/gdansk01/gateway8.aps - 20k >. Acessado em 02/10/2016.

CASARIL, C. C. A Dinâmica da Rede Urbana de Francisco Beltrão - Paraná. 2014. Tese (Doutorado em Geografia). Universidade Federal de Santa Catarina, Florianópolis, 2014.

CHRISTALLER, W. Central Places in Southern Germany. Prentice-Hall, Inc. Englewood Cliffs, 1966.

CORRÊA, R. L. A rede urbana. São Paulo: Ática, 1989. 96p.

Interações espaciais. In: CASTRO, I. E. de; GOMES, P. C. da C.;

CORRÊA, R. L. Explorações geográficas: percursos no fim do século. RJ: Bertrand Brasil, 1997, p.279-318.

. Globalização e reestruturação da rede urbana: uma nota sobre as

pequenas cidades. Território, Rio de Janeiro, v.4, n.6, p. 43-52, jan./jun. 1999.

DINIZ, C. C; SANTOS, F; CROCCO, M. Conhecimento, inovação e desenvolvimento regional/local. In: DINIZ, C.C.; CROCCO, M. (Org.). Economia Regional e Urbana: Contribuições Teóricas Recentes. Belo Horizonte: Editora BFMG, 2006.

FRESCA, T. M. A rede urbana do norte do Paraná. Londrina: Eduel, 2004. 403p. v.19, n.2, 2010.

Rede Urbana e Divisão Territorial do Trabalho. Geografia (Londrina),

IBGE. Regiões de influência das cidades 2007. RJ: IBGE, 2008. 201p. Disponível em <http://www.ibge.gov.br/home/geociencias/geografia/regic.shtm>. Acesso em 12/10/10.

. Regiões de influência das cidades 1993. Rio de Janeiro: IBGE, $2000 \mathrm{~b}$. 230p. Disponível em <http://biblioteca.ibge.gov.br>. Acesso em 28/03/2010. 
Censo demográfico - 2010. Rio de Janeiro: IBGE, 2010. Disponível em <http://censo2010.ibge.gov.br>. Acessado em 12/06/2011.

LOPES, Roberto Paulo Machado. Universidade Pública e Desenvolvimento Local: uma abordagem a partir dos gastos da Universidade Estadual do Sudoeste da Bahia. 2001. Dissertação. (Mestrado em Economia) Universidade Federal da Bahia, Salvador, 2001.

MARINHO, A. Avaliação organizacional de uma Universidade Pública: uma abordagem não paramétrica da Universidade Federal do Rio de Janeiro. 1996, $244 f$. Tese (Doutorado em Economia) - EPGE - FGV, Rio de Janeiro, 1996.

OECD. Understanding the regional contribuion of higher education institutions: a literature review. Education Working Paper, n.9, jul. 2007. Disponível em:

$<$ http://search.oecd.org/officialdocuments/publicdisplaydocumentpdf/?cote=EDU/WK

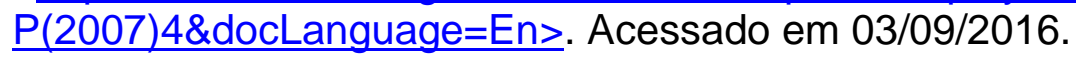

RAIHER, A. P. (Org.) As universidades Estaduais e o desenvolvimento regional do Paraná. Ponta Grossa: Ed. UEPG, 2015.

ROLIM, C; SERRA, M. Impacto econômico das universidades estaduais do Paraná. Economia \& Tecnologia, textos para Discussão, n.25, 2005.

SANTOS, M. Espaço e método. São Paulo: Nobel, 1985.

. A urbanização brasileira. São Paulo: Hucitec, 1993.

SHIKIDA, P. F. A; PARRÉ, J. L; CARMO, A. S. S; RAIHER, A. P; HIGACHI, H. Y; COELHO, M. H. A importância das Universidades Estaduais no desenvolvimento econômico dos municípios do Paraná: Análise do efeito de médio e longo prazo. In:

RAIHER, A. P. (Org.) As universidades Estaduais e o desenvolvimento regional do Paraná. Ponta Grossa: Ed. UEPG, 2015. p.75-114.

SOUZA, M. L. de. ABC do desenvolvimento urbano. RJ: Bertrand Brasil, 2003.

SPOSITO, M. E. B. A gestão do território e as diferentes escalas da centralidade urbana. Revista Território. RJ: Garamond, ano III, n.4, p.27-37, jan./jun. 1998.

Disponível em <http://www.revistaterritorio.com.br/pdf/04 3 sposito.pdf $>$. Acesso em 20/07/2010.

\section{NOTAS DE AUTOR}

CONTRIBUIÇÃO DE AUTORIA

Carlos Cassemiro Casaril - Concepção. Coleta de dados, Análise de dados, Elaboração do manuscrito.

\section{FINANCIAMENTO}

Apoio financeiro da Coordenação de Aperfeiçoamento de Pessoal de Nível Superior (CAPES), através da Bolsa do Programa Nacional de Pós-doutorado (PNPD), com pesquisa vinculada a UNIOESTE, Francisco Beltrão, PR.

CONSENTIMENTO DE USO DE IMAGEM

Não se aplica

APROVAÇÃO DE COMITÊ DE ÉTICA EM PESQUISA

Não se aplica

CONFLITO DE INTERESSES

Não se aplica

Este artigo está licenciado sob a Licença Creative Commons CC-BY. Com essa licença você pode compartilhar, 
adaptar, criar para qualquer fim, desde que atribua a autoria da obra.

\section{HISTÓRICO}

Recebido em: 08-02-2018

Aprovado em: 16-08-2018 